\title{
Karakteristik dan Pemenuhan CPPOB Pelaku UMKM Online Produk Olahan Beku Daging Sapi dan Ayam di DKI Jakarta
}

\author{
Characteristics and GMP Fulfillment of Online Small and Medium Enterprises (SMEs) with Product of \\ Frozen Processed Beef and Chicken in DKI Jakarta \\ R. Pritanova $\mathbf{P}^{1}$, T. Muhandri ${ }^{2,3^{*}}$, \& S. Nurjanah ${ }^{2,3}$ \\ ${ }^{1}$ Program Magister Teknologi Pangan, Departemen Ilmu dan Teknologi Pangan, Fakultas Teknologi \\ Pertanian, IPB University \\ ${ }^{2}$ Departemen Ilmu dan Teknologi Pangan, Fakultas Teknologi Pertanian, IPB University \\ ${ }^{3}$ Southeast Asian Food and Agricultural Science and Technology (SEAFAST) Center, IPB University \\ Jl. Meranti, Kampus IPB Darmaga Bogor 16680, Indonesia \\ *Corresponding author: cahyomuhandri@yahoo.com \\ (Received 24-06-2020; Revised 09-07-2020; Accepted 03-08-2020)
}

\begin{abstract}
Online trading system impacts small and medium entreprsises (SMEs) to easily sell food products and make the sales of processed food and beverage product in Indonesia continues to grow, however their awareness to implement food safety standards is still considered as low. This research was aimed to determine the characteristic and Good Manufacturing Practices (GMP) fulfillment of online SMEs with frozen processed beef and chicken products that is included in medium risk registration categories with BPOM MD authorization. Research methods include sample selection of 24 SMEs respondents in DKI Jakarta with snowball sampling method, questionnaire distribution, field observations and data processing using descriptive analysis. Analysis of GMP fulfillment by MSMEs is based on eight requirements refer to Ministry of Industry Regulation Number 75/M-IND/PER/7/2010 concerning GMP guidelines. Results showed that $41.7 \%$ the leader had bachelor degree and $54.2 \%$ total assets under 5 million rupiah with annual turnover under 50 million rupiah. Most of them had IUMK (62.5\%), production room located in household kitchen (54.2\%) and selling online through social media (95.8\%). 79.2\% of respondents slightly understand about GMP and food safety concept. The most uncomplied from eight requirements of GMP was application of lamp protectors in the production room (91.7\%).
\end{abstract}

Keywords: CPPOB, e-commerce, frozen food, GMP, SMEs

\begin{abstract}
ABSTRAK
Sistem perdagangan online mempengaruhi kemudahan UMKM pangan dalam menjual produknya dan berdampak pada meningkatnya penjualan pangan olahan di Indonesia, namun kesadaran UMKM dalam menerapkan standar keamanan pangan masih dianggap rendah. Penelitian ini bertujuan untuk mengetahui karakteristik dan pemenuhan Cara Produksi Pangan Olahan yang Baik (CPPOB) pelaku UMKM online produk olahan beku daging sapi dan ayam yang termasuk ke dalam produk pangan dengan kategori risiko pendaftaran sedang dengan izin edar BPOM MD. Metode penelitian berupa pemilihan 24 responden UMKM online di DKI Jakarta dengan metode snowball sampling, penyebaran kuesioner, observasi lapangan dan pengolahan data menggunakan analisis deskriptif. Analisis pemenuhan CPPOB oleh UMKM didasarkan pada 8 persyaratan yang merujuk ke Peraturan Menteri Perindustrian Republik Indonesia Nomor 75/M-IND/PER/7/2010 tentang Pedoman CPPOB. Hasil penelitian menunjukkan 41.7\% pimpinan UMKM adalah lulusan Strata-1 dan 54.2\% memiliki total aset mesin di bawah 5 juta rupiah dengan omzet per tahun di bawah 50 juta rupiah. Sebagian besar memiliki IUMK (62.5\%), lokasi produksi di dapur rumah tangga (54.2\%) dan berjualan online melalui media sosial $(95.8 \%)$. Sebanyak $79.2 \%$ responden sedikit paham tentang CPPOB dan konsep keamanan pangan. Dari 8 persyaratan, yang paling banyak ditemukan tidak memenuhi persyaratan СРРОВ adalah tidak adanya pelindung lampu di ruang produksi (91.7\%).
\end{abstract}

Kata kunci : CPPOB, e-commerce, frozen food, GMP, UMKM 


\section{PENDAHULUAN}

Teknologi komunikasi yang semakin berkembang saat ini membuat sistem perdagangan online menjadi salah satu pilihan bagi pelaku usaha. Sistem perdagangan online ini secara tidak langsung membuat pelaku bisnis makanan dapat menjual produk pangan secara bebas dan dengan mudah mendapatkan atensi pasar. Hasil penjualan atau omzet produk makanan dan minuman olahan di Indonesia terus meningkat dari sekitar 500 triliun rupiah di tahun 2008 menjadi sekitar 1000 triliun rupiah di tahun 2015 (Hedynata \& Radianto 2016). Peluang bisnis di industri makanan dan minuman olahan yang sangat positif berdampak pada meningkatnya jumlah pelaku UMKM bidang pangan secara signifikan.

Di Indonesia, saat ini, terdapat dua undang-undang yang menjadi acuan bagi pelaku usaha dalam melakukan transaksi perdagangan baik yang konvensional maupun online, yaitu Undang-Undang Nomor 7 Tahun 2014 tentang Perdagangan (UU Perdagangan) dan Undang-Undang Nomor 8 Tahun 1999 tentang Perlindungan Konsumen (UU Perlindungan Konsumen). E-Commerce diatur dalam UU Perdagangan Bab VIII mengenai Perdagangan Melalui Sistem Elektronik pada pasal 65 dan 66. UU Perlindungan Konsumen menjadi acuan terhadap kedua belah pihak agar proses perdagangan berjalan adil dan tidak merugikan konsumen. Perlindungan konsumen menjadi suatu hal yan penting di era perdagangan online, modal asas kepercayaan dalam transaksi perdagangan e-commerce dapat menjadi celah bagi pedagang yang tidak bertanggung jawab dalam memasarkan produknya (Pariadi 2018).

Kementerian Koperasi dan Usaha Kecil Menengah (UKM) mencatat kontribusi sektor UMKM terhadap Produk Domestik Bruto (PDB) meningkat dari 57.84\% menjadi $60.34 \%$. Sektor kuliner dianggap paling besar berkontribusi terhadap PDB yaitu sebesar 209 triliun rupiah atau 32.50\%. UMKM menyerap banyak tenaga kerja hingga mencapai $97.22 \%$ dalam 5 tahun terakhir.

Survei yang dilakukan oleh Kementerian Pertanian pada tahun 2015 mengatakan bahwa pola konsumsi daging olahan meningkat $10.28 \%$ setiap tahunnya di Indonesia. Produk frozen food seperti bakso, sosis dan nugget merupakan produk yang paling banyak dikonsumsi sehingga berpengaruh pada meningkatnya kebutuhan daging ayam dan sapi (Santoso et al. 2018). Hartanto \& Prabawa (2020) menyatakan bahwa peluang pasar frozen food saat ini terbuka lebar karena gaya hidup masyarakat perkotaan di Indonesia yang memprioritaskan kepraktisan. Konsumen mempunyai hak untuk mendapatkan informasi yang jujur, jelas dan benar terkait produk yang akan dibeli. Produsen pangan harus mencantumkan informasi yang lengkap dan jelas terkait produknya (Santoso et al. 2018), termasuk kepatuhan produk tersebut terhadap regulasi pemerintah.

Kesadaran pelaku UMKM untuk menerapkan standar keamanan pangan pada produk yang dijualnya masih dianggap rendah. Data yang dilansir BPOM pada tahun 2017 menunjukkan bahwa dari 2352 IRTP (Industri Rumah Tangga Pangan), baru 10.97\% yang sudah melakukan Cara Produksi Pangan Olahan yang Baik (CPPOB) (Nurcahyo
2018). CPPOB adalah suatu pedoman yang menjelaskan bagaimana memproduksi pangan agar bermutu, aman dan layak untuk dikonsumsi. CPPOB juga menjadi persyaratan dasar pemberian sertifikat izin edar MD oleh BPOM. Direktorat Pengawasan Pangan Risiko Rendah dan Sedang BPOM RI menyatakan bahwa produk olahan beku daging sapi dan ayam yang beredar di Indonesia masuk ke dalam pangan dengan kategori risiko pendaftaran sedang dan wajib memiliki izin edar BPOM MD. Kewajiban pangan olahan yang diedarkan secara online untuk memiliki izin edar dan memenuhi cara produksi yang baik sesuai dengan ketentuan peraturan perundang-undangan tertuang dalam Peraturan BPOM Nomor 8 Tahun 2020 tentang Pengawasan Obat dan Makanan yang Diedarkan Secara Daring.

Perilaku masyarakat terhadap e-commerce, pola konsumsinya terhadap hasil olahan ternak khususnya daging sapi dan ayam serta kesadaran pelaku UMKM yang masih dianggap rendah dalam menerapkan standar keamanan pangan menjadi dasar dilakukannya penelitian ini. Penelitian ini bertujuan untuk mengetahui karakteristik dan pemenuhan CPPOB pelaku UMKM online produk olahan beku daging sapi dan ayam yang termasuk ke dalam produk pangan dengan kategori risiko pendaftaran sedang dengan izin edar BPOM MD.

\section{MATERI DAN METODE}

\section{Waktu dan Lokasi Penelitian}

Penelitian dilakukan dari bulan Februari sampai dengan bulan Mei tahun 2020 dan bertempat di lokasi produksi UMKM online produk olahan beku daging sapi dan ayam di DKI Jakarta.

\section{Alat dan Bahan}

Alat dan bahan yang akan digunakan dalam penelitian ini adalah laptop untuk menyebarkan kuesioner online dan juga mengumpulkan data hasil wawancara dan kuesioner. Dokumen Peraturan Menteri Perindustrian Republik Indonesia Nomor 75/M-IND/PER/7/2010 tentang Pedoman Cara Produksi Pangan Olahan yang Baik juga digunakan dalam penelitian ini.

\section{Metode}

Penelitian terdiri dari beberapa tahapan yaitu identifikasi dan pemilihan sampel, pengambilan data, analisis deskriptif dan pembahasan. Tahap pertama yang dilakukan adalah identifikasi dan pemilihan sampel UMKM online produk olahan beku daging sapi dan ayam di DKI Jakarta sebanyak 24 UMKM (Muhandri et al. 2016) mengacu kepada penelitian serupa terhadap UMKM Pangan di Palu, Sulawesi Tengah.

Metode snowball sampling dilakukan pada penelitian ini untuk menemukan sampel yang sulit diakses atau mendapatkan data terkait masalah yang spesifik hingga dapat ditemukan responden yang sesuai sasaran penelitian melalui hubungan dalam sebuah jaringan sampai jumlah sampel yang dibutuhkan tercapai (Nurdiani 2014). Pengambilan data dilakukan dengan cara penyusunan kuesioner dan analisis pemenuhan CPPOB oleh UMKM. 
1. Penyusunan kuesioner

Kuesioner untuk responden UMKM akan dibagi menjadi dua bagian yaitu latar belakang pimpinan dan sejarah pendirian usaha serta pemahaman pimpinan terhadap CPPOB dan konsep dasar keamanan pangan. Bagian pemahaman pimpinan terhadap CPPOB dan konsep dasar keamanan pangan menghasilkan nilai yang nantinya dikelompokkan ke dalam kategori paham, sedikit paham, dan tidak paham. Paham yaitu mendapatkan skor sebesar 8 sampai 10 poin, sedikit paham yaitu mendapatkan skor pada sebesar 4 sampai 7 poin dan tidak paham yaitu mendapatkan skor sebesar 0 sampai 3 poin (Muhandri et al. 2016). Kuesioner disebarkan secara langsung ke 16 UMKM dengan metode wawancara mendalam (Ngwa, 2017) dan secara tidak langsung (online) ke 8 UMKM karena situasi yang tidak memungkinkan untuk dikunjungi ke lokasi produksi.

\section{Analisis pemenuhan $\mathrm{CPPOB}$ oleh UMKM}

Analisis pemenuhan CPPOB oleh UMKM didasarkan pada delapan persyaratan yang merujuk ke Peraturan Menteri Perindustrian Republik Indonesia Nomor 75/M-IND/PER/7/2010 tentang Pedoman Cara Produksi Pangan Olahan yang Baik. Analisis ini ditujukan untuk melihat pemenuhan awal UMKM terhadap CPPOB. Sebanyak 16 UMKM dianalisis secara langsung ke lokasi produksi dan 8 UMKM dianalisis secara tidak langsung (online) karena situasi yang tidak memungkinkan untuk dikunjungi ke lokasi produksi. Delapan persyaratan tersebut merupakan gabungan dari beberapa aspek penting yang meningkatkan risiko kontaminasi pangan dan penyakit bawaan pangan di negara berkembang yaitu infrastruktur keamanan pangan yang tidak memadai, standar kebersihan yang buruk, kurangnya teknik penjaminan mutu produk dan penggunaan bahan baku yang terkontaminasi (Mukantwali et al. 2013). Lyimo (2017) juga menilai karakteristik lantai, langit-langit dan tembok bangunan, pengendalian hama dan penggunaan label yang tepat pada pemenuhan Good Manufacturing Practices (GMP) di pabrik penggilingan jagung skala kecil di Tanzania. Delapan persyaratan tersebut terdiri dari kombinasi persyaratan dengan tingkatan "dapat", "seharusnya" dan "harus" seperti tertuang di Tabel 1.

Tabel 1. Delapan persyaratan CPPOB yang dipilih dan tingkatan persyaratannya

\begin{tabular}{ll}
\hline Ruang lingkup persyaratan pedoman CPPOB & $\begin{array}{l}\text { Tingkatan } \\
\text { persyaratan }\end{array}$ \\
\hline $\begin{array}{l}\text { Pemeliharaan dan Program sanitasi } \\
\text { (program pengendalian hama) }\end{array}$ & Seharusnya \\
Bangunan (struktur ruangan - lantai) & Seharusnya \\
Bangunan (struktur ruangan - dinding) & Seharusnya \\
Bangunan (struktur ruangan - atap dan & Seharusnya \\
langit-langit) & \\
Bangunan (struktur ruangan - atap dan & Seharusnya \\
langit-langit - penerangan) & \\
Fasilitas sanitasi (toilet) & Seharusnya \\
Laboratorium (kepemilikan laboratorium) & Dapat, \\
Label dan keterangan produk & Seharusnya \\
\hline
\end{tabular}

Persyaratan "dapat" adalah persyaratan yang mengindikasikan apabila tidak dipenuhi akan mempunyai potensi yang kurang berpengaruh terhadap keamanan produk. Persyaratan "seharusnya" adalah persyaratan yang mengindikasikan apabila tidak dipenuhi akan mempunyai potensi yang berpengaruh terhadap keamanan produk. Persyaratan "harus" adalah persyaratan yang mengindikasikan apabila tidak dipenuhi akan mempengaruhi keamanan produk secara langsung.

Data yang menggambarkan karakteristik dan pemahaman UMKM online terhadap CPPOB dan konsep dasar keamanan pangan serta pemenuhannya terhadap persyaratan CPPOB akan dianalisis secara deskriptif (Maryati et al. 2016). Data ditabulasi, diolah dan ditampilkan dalam bentuk tabel atau histogram dengan menggunakan program Microsoft Excel (Ernawati 2018). Evaluasi yang akan dilakukan adalah analisa karakteristik, pemahaman dan pemenuhan CPPOB oleh UMKM online serta faktor yang mempengaruhi penerapan CPPOB.

\section{HASIL DAN PEMBAHASAN}

\section{Karakteristik UMKM Online Produk Olahan Beku Daging Sapi dan Ayam di DKI Jakarta}

Karakteristik UMKM online produk olahan beku daging sapi dan ayam di DKI Jakarta dikaji melalui beberapa pendekatan yaitu hubungan latar belakang pendidikan dengan masa usaha, hubungan aset mesin produksi dengan omzet per tahun, aspek legalitas yang dimiliki UMKM, lokasi produksi dan platform online yang digunakan untuk berjualan.

Latar belakang pendidikan pelaku UMKM online didominasi oleh lulusan S-1 dengan masa usaha paling banyak di bawah 5 tahun (Tabel 2). Pimpinan dengan latar belakang lulusan S-2 memiliki masa usaha minimum 5 tahun sampai dengan kurang dari 15 tahun. Utari \& Dewi (2014) mengungkapkan pelaku UMKM di Denpasar Barat didominasi oleh lulusan S-1. Indoworo (2016) juga menyatakan bahwa $16.9 \%$ pengguna internet di Indonesia memiliki latar belakang pendidikan S-1. Tidak ada keterkaitan antara tingginya latar belakang pendidikan dengan masa usaha, 1 orang responden lulusan SMA memiliki masa usaha paling tinggi yaitu di atas 15 tahun.

Tabel 2. Hubungan antara latar belakang pendidikan dengan masa usaha pelaku UMKM

\begin{tabular}{lccccc}
\hline Latar & \multicolumn{5}{c}{ Masa Usaha (tahun) } \\
\cline { 2 - 6 } $\begin{array}{l}\text { Belakang } \\
\text { Pendidikan }\end{array}$ & $<5$ & $5-<10$ & $10-<15$ & $>15$ & Total n (\%) \\
\hline SMP & 0 & 1 & 0 & 0 & $1(4.2 \%)$ \\
SMA & 6 & 2 & 0 & 1 & $9(37.5 \%)$ \\
D3/D4 & 1 & 0 & 0 & 0 & $1(4.2 \%)$ \\
S1 & 9 & 1 & 0 & 0 & $10(41.7 \%)$ \\
S2 & 0 & 2 & 1 & 0 & $3(12.5 \%)$ \\
Total n & 16 & 6 & 1 & 1 & $24(100 \%)$ \\
$(\%)$ & $(66.7 \%)$ & $(25 \%)$ & $(4.2 \%)$ & $(4.2 \%)$ \\
\hline
\end{tabular}


Menurut Nainggolan (2016) latar belakang pendidikan dan lama usaha tidak memberikan pengaruh terhadap penghasilan UMKM di Surabaya.

Responden yang memiliki aset di atas 50 juta rupiah memiliki omzet yang lebih tinggi per tahunnya yaitu mulai dari 50-200 juta rupiah per tahunnya, sementara yang memiliki aset lebih rendah untuk mesin utama memiliki total omzet per tahun yang lebih rendah yaitu mulai dari $<50$ juta rupiah per tahunnya (Tabel 3). Maryati et al. (2016) mengungkapkan bahwa pelaku UMKM makanan beku di Jabodetabek didominasi oleh pelaku usaha dengan omzet di bawah 50 juta per tahun dan aset mesin di bawah 50 juta rupiah. Hal ini menunjukkan bahwa kelompok UMKM mayoritas adalah kelompok usaha mikro dengan produk yang masih belum stabil mutu dan ukurannya karena mesin yang digunakan walaupun sudah berbasis teknologi namun masih sangat sederhana. Hal ini sejalan dengan data dari Kementerian Koperasi dan UKM tahun 2018 yang menyebutkan bahwa total jumlah UMKM di Indonesia adalah 64 juta unit dengan 63 juta unit tergabung dalam unit usaha mikro, yaitu usaha yang asetnya di luar tanah dan bangunan tempat usaha kurang dari 50 juta rupiah dan omzet per tahunnya maksimum 300 juta rupiah.

Tabel 3. Total aset mesin utama dan total omzet per tahun

\begin{tabular}{lcccc}
\hline \multirow{2}{*}{$\begin{array}{l}\text { Total aset } \\
\text { mesin } \\
\text { utama (Rp) }\end{array}$} & \multicolumn{4}{c}{ Total omzet per tahun (Rp) } \\
\cline { 2 - 5 } & $\begin{array}{c}<0 \text { juta/ } \\
\text { tahun }\end{array}$ & $\begin{array}{c}50-200 \\
\text { juta/tahun }\end{array}$ & $\begin{array}{c}>200 \text { juta/ } \\
\text { tahun }\end{array}$ & Total n (\%) \\
\hline$<5$ juta & 9 & 3 & 1 & $13(54.2 \%)$ \\
$5-50$ juta & 4 & 3 & 1 & $8(33.3 \%)$ \\
$>50$ juta & 0 & 2 & 1 & $3(12.5 \%)$ \\
Total n & 13 & 8 & 3 & $24(100 \%)$ \\
$(\%)$ & $(54.2 \%)$ & $(33.3 \%)$ & $(12.5 \%)$ & \\
\hline
\end{tabular}

Aspek legalitas usaha yang dimiliki UMKM ditandai dengan kepemilikan IUMK (Izin Usaha Mikro Kecil), sertifikat Halal MUI dan juga izin edar BPOM MD. IUMK adalah tanda legalitas dari negara kepada pelaku usaha mikro dan kecil, sertifikasi Halal MUI menandakan bahwa proses produksi pangan olahan beku daging sapi dan ayam sudah dilakukan sesuai syariat Islam karena mayoritas penduduk Indonesia adalah Muslim, sementara izin edar BPOM MD menjadi indikator bahwa produk pangan sudah disetujui oleh pemerintah untuk beredar di Indonesia karena produk pangan olahan asal hewan yang disimpan dingin atau beku tidak diperkenankan memperoleh izin edar PIRT sesuai peraturan Peraturan BPOM Nomor 22 Tahun 2018.

Pada Tabel 4 tampak bahwa aspek legalitas yang paling banyak dimiliki adalah IUMK. Sertifikat Halal MUI belum dimiliki oleh sebagian besar UMKM online, hal ini sesuai dengan penelitian Ma'rifat \& Sari (2017) yang menyatakan proses penggilingan daging oleh UMKM di pasar atau di tempat yang belum tersertifikasi halal dapat menjadi penghambat untuk penerapan Sistem Jaminan Halal. Izin edar BPOM MD hanya dimiliki oleh 1 orang responden (4.2\%). Responden yang belum memiliki izin edar BPOM MD mengaku bahwa mereka ingin
Tabel 4. Perlakuan terhadap aspek legalitas usaha dan lokasi produksi

\begin{tabular}{lcc}
\hline Aspek penilaian & Jumlah responden & Persentase \\
\hline Legalitas Usaha & 15 & $62.50 \%$ \\
IUMK & 7 & $29.20 \%$ \\
Halal MUI & 1 & $4.20 \%$ \\
BPOM MD & & \\
Lokasi produksi & 13 & $54.20 \%$ \\
$\quad \begin{array}{l}\text { Dapur yang menjadi satu } \\
\text { dengan dapur rumah } \\
\text { tangga }\end{array}$ & & \\
$\begin{array}{l}\text { Dapur yang terpisah dari } \\
\text { dapur rumah tangga } \\
\text { namun berada di dalam }\end{array}$ & 6 & $25 \%$ \\
satu rumah tinggal & & \\
$\begin{array}{l}\text { Dapur yang terpisah dari } \\
\text { rumah tinggal }\end{array}$ & 5 & $20.80 \%$ \\
\hline
\end{tabular}

mendaftarkan produk mereka agar memiliki izin edar BPOM MD (78.3\%) dan namun 21.7\% mengaku tidak ingin mendaftarkan produk mereka karena alasan bahwa bisnis yang mereka jalani hanya bisnis sampingan. Maryati et al. (2016) mengungkapkan bahwa meskipun IUMK bisa didapatkan secara gratis dari kecamatan namun UMKM makanan beku menganggap bahwa prosesnya masih rumit sementara izin edar BPOM MD yang dinilai sangat ketat pelaksanaannya membuat pelaku usaha menyerah sebelum mengajukan

Lokasi produksi yang digunakan oleh UMKM tertera pada Tabel 4. Hal ini sejalan dengan penelitian dari Maryati et al. (2016) bahwa pelaku usaha makanan beku masih didominasi dengan lokasi produksi di rumah sendiri dan di dapur yang menjadi satu dengan dapur rumah tangga. Lokasi produksi yang masih menjadi satu dengan dapur rumah tangga disebabkan karena keterbatasan ruang yang ada di tempat tinggal pelaku UMKM.

Gambar 1 menunjukkan platform online yang paling banyak digunakan oleh UMKM online untuk memasarkan produknya. Sosial media yang digunakan untuk bejualan adalah Instagram dan Facebook. Portal e-commerce yang digunakan untuk memasarkan produknya adalah Tokopedia, Shopee, Elevania, Blibli, Bukalapak, Lazada, Ralali dan Q10. Hal ini sesuai dengan penelitian Permana dan Cendana (2019) yang menyatakan bahwa pelaku UMKM telah menggunakan sosial media Instagram dan marketplace Shopee dari awal mereka berjualan. Chat Messenger yang digunakan untuk memasarkan produk adalah Whatsapp dan Telegram. Aplikasi pengantaran makanan yang digunakan untuk memasarkan produk adalah Gofood dan Grabfood. Keberlanjutan bisnis UMKM tergantung pada peningkatan dan kestabilan jumlah transaksi, maka dari itu diperlukan strategi pemasaran yang baik melalui sosial media dan nonsosial media agar meningkatkan jumlah transaksi (Permana \& Cendana 2019). Menurut Prastiwi et al. (2017) jumlah konsumen nugget ayam di Kecamatan Secang Kabupaten Magelang paling banyak dimiliki oleh rentang usia antara 20-25 tahun. Rentang usia tersebut dianggap rentang usia 


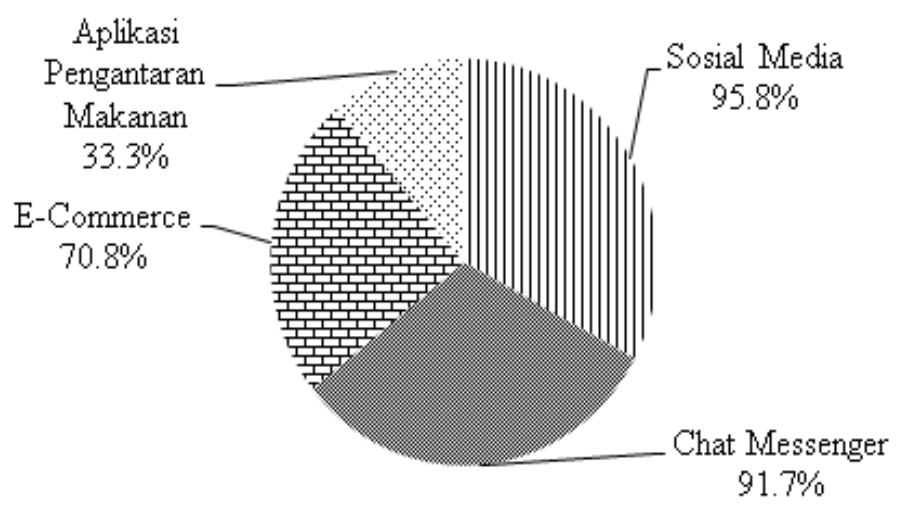

Gambar 1. Platform online yang digunakan UMKM untuk berjualan

produktif yang cenderung mengkonsumsi produk olahan pangan yang praktis. Indoworo (2016) menjelaskan bahwa rentang usia pengguna internet di Indonesia mayoritas berusia 18-25 tahun, sehingga strategi pemasaran produk olahan beku daging sapi dan ayam menggunakan teknologi internet sudah tepat sasaran.

\section{Pemahaman dan Pemenuhan UMKM Online terhadap CPPOB}

Identifikasi pemahaman CPPOB oleh UMKM menunjukkan pemahaman responden didominasi oleh sedikit paham (Tabel 5). Lyimo (2017) dalam penelitiannya menyatakan bahwa $92.2 \%$ pelaku industri kecil di Turki dan $40 \%$ pelaku industri kecil dan menengah di Inggris tidak paham tentang Good Manufacturing Practices (GMP) atau CPPOB. Pemahaman UMKM terhadap teknologi produksi dan pengendalian mutu yang masih kurang disebabkan oleh minimnya kesempatan untuk mengikuti perkembangan teknologi dan juga kurangnya pendidikan dan pelatihan (Hapsari 2014). Singh et al. (2018) membuktikan bahwa pemahaman karyawan terhadap Good Manufacturing Practices (GMP) meningkat setelah dilakukan pelatihan selama dua hari.
Tabel 5. Pemahaman UMKM online terhadap CPPOB dan konsep keamanan pangan

\begin{tabular}{lc}
\hline $\begin{array}{l}\text { Pemahaman terhadap CPPOB dan konsep } \\
\text { keamanan pangan }\end{array}$ & Total n $(\%)$ \\
\hline Tidak paham & $1(4.2 \%)$ \\
Sedikit paham & $19(79.2 \%)$ \\
Paham & $4(16.7 \%)$ \\
\hline
\end{tabular}

Karakteristik UMKM yang didominasi lulusan S-1 diharapkan dapat lebih mudah untuk memahami dan mengimplementasikan pelatihan atau pembinaan yang diberikan (Maryati et al. 2016).

Berdasarkan Gambar 2, kendala UMKM online dalam pemenuhan CPPOB paling banyak terjadi pada tidak tersedianya pelindung lampu di ruang produksi. Mukantwali et al. (2013) menyatakan bahwa penerangan natural ataupun buatan adalah faktor yang penting dalam industri pengolahan pangan namun perlengkapan pencahayaan harus dilindungi untuk mencegah kontaminasi dari kerusakan terhadap produk pangan. Lampu yang tidak dilengkapi pelindung dapat mencemari produk pangan apabila kotor atau pecah.

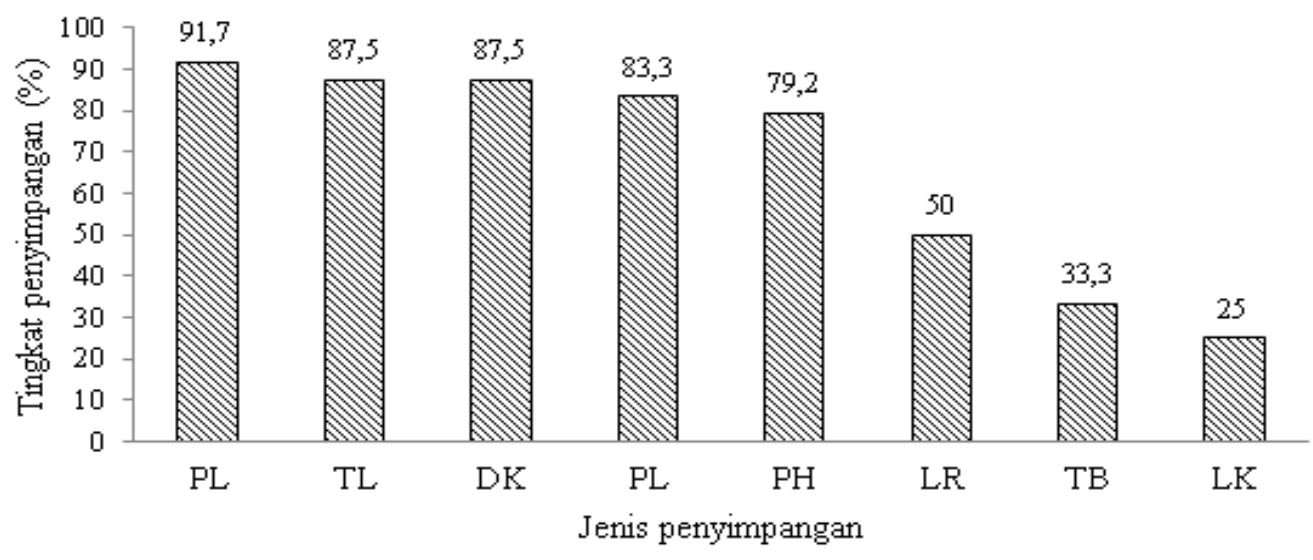

Gambar 2. Penyimpangan UMKM terhadap CPPOB. PL = Pelindung lampu; $\mathrm{TL}=$ Tes laboratorium bahan baku dan akhir; DK = Dinding kedap air hingga 1.70 M; PL = Penggunaan label yang benar; PH = Pengendalian hama yang efektif; LR = Langit-langit retak/bocor/tidak rata; TB = Toilet berhadapan langsung dengan ruang produksi; $\mathrm{LK}=$ Lantai kedap air. 
Kendala berikutnya adalah UMKM tidak melakukan pengujian laboratorium untuk bahan baku dan bahan jadi. Muhandri et al. (2016) menyatakan bahwa aspek pengujian bahan baku dan produk akhir pada UMKM di Palu menjadi kendala karena tidak adanya laboratorium uji di Palu dan juga kendala biaya. Besar penyimpangan yang sama juga terjadi pada persyaratan untuk memiliki dinding yang kedap air hingga ketinggian 1.70 meter. Sebanyak 12.5\% usaha kecil dan $36.4 \%$ usaha menengah pengolahan nanas di Rwanda memiliki dinding yang dicat dengan cat berbasis minyak sehingga dinding menjadi kedap air (Mukantwali et al. 2013).

Sebanyak $83.3 \% \quad$ UMKM online belum menggunakan label produk yang benar dan dipersyaratkan oleh BPOM. Berdasarkan Peraturan BPOM No 27 Tahun 2017 tentang Pendaftaran Pangan Olahan, pencantuman label pada kemasan produk pangan olahan paling sedikit memuat keterangan mengenai nama produk, daftar bahan yang digunakan, berat bersih, nama dan alamat produsen, halal bagi yang dipersyaratkan, tanggal dan kode produksi, tanggal, bulan dan tahun kedaluwarsa, nomor izin edar dan asal usul bahan pangan tertentu. Hal ini selaras dengan pernyataan dari Wijaya \& Rahayu (2014) bahwa tingkat pemenuhan pelabelan oleh IRTP di Bogor menunjukkan bahwa masih diperlukannya pembinaan lebih lanjut mengenai kriteria pelabelan sesuai dengan regulasi yang berlaku.

Aplikasi pengendalian hama yang efektif juga belum diterapkan oleh $79.2 \%$ responden. Aplikasi pengendalian hama yang efektif diindikasikan dengan adanya prosedur pengontrolan hama yang baku misalnya dengan penggunaan pihak ketiga dalam jangka waktu yang disepakati sesuai dengan kondisi lingkungan. Kendala berikutnya yaitu sebanyak 50\% UMKM memiliki langit-langit yang retak, bocor ataupun tidak rata pada ruang produksinya. Sebanyak $33.3 \%$ UMKM juga memiliki toilet yang berhadapan atau berhubungan langsung dengan ruang produksi. Persyaratan BPOM mengharuskan toilet yang berdekatan dengan ruang produksi harus diberikan sekat atau pembatas. Kendala terakhir yang dihadapi oleh $25 \%$ responden adalah ruang produksi yang belum memiliki lantai yang kedap air.

Mukantwali et al. (2013) menyatakan pada usaha kecil dan menengah pengolahan nanas di Rwanda, 93.8\% usaha kecil dan $90.9 \%$ usaha menengah belum mempunyai sistem pengendalian hama, $68.8 \%$ usaha kecil dan $27.3 \%$ usaha menengah memiliki keretakan pada langit-langit ruang produksinya, 68.8\% usaha kecil dan 36.4\% usaha menengah tidak memiliki wilayah bersih dan kotor yang terpisah dan $18.8 \%$ usaha kecil tidak memilki lantai yang kedap air. Thaheer et al. (2015) menjelaskan bahwa dua dari empat faktor yang dinilai belum memenuhi syarat untuk UMKM pengolahan ikan pindang terhadap GMP adalah tata letak dan penataan pabrik serta pengendalian hama. Perdana (2018) dalam penelitiannya juga merekomendasikan perbaikan dinding dan lantai sesuai aturan kemanan pangan perlu dilakukan untuk penerapan GMP di pabrik pengolahan pangan tradisional di Cianjur.

Persyaratan terkait tata letak dan bangunan ruang produksi masih menjadi kendala UMKM dalam proses pengurusan izin edar BPOM MD karena membutuhkan biaya yang tidak sedikit dan juga ruang yang terbatas. Singh et al. (2018) dalam penelitiannya terhadap usaha kecil dan menengah di Malaysia menyimpulkan bahwa kepatuhan terhadap desain lokasi dan peralatan menimbulkan kebingungan bagi pelaku usaha karena biaya yang besar untuk pemeliharaan, kebersihan dan renovasi. BPOM RI yang diwakili oleh Direktorat Pengawasan Pangan Risiko Rendah dan Sedang mengkonfirmasi bahwa saat ini CPPOB memang mengacu pada Peraturan Menteri Perindustrian No. 75 Tahun 2010 yang dituangkan ke dalam Form A-166 Tahun 2002, namun saat ini form tersebut sedang dalam pengembangan untuk penyederhanaan yang diperuntukkan kepada UMKM tanpa mengurangi aspek keamanan pangan secara umum di industri pangan.

\section{KESIMPULAN}

Karakteristik UMKM didominasi oleh pimpinan dengan latar belakang pendidikan S-1, masa usaha di bawah 5 tahun, total aset mesin utama di bawah 5 juta rupiah dan omzet per tahun di bawah 50 juta rupiah. Legalitas usaha yang dimiliki paling banyak adalah IUMK dengan lokasi produksi di dapur yang menyatu dengan dapur rumah tangga dan berjualan online melalui sosial media Instagram dan Facebook. Sebagian besar responden sedikit paham terkait CPPOB dan konsep keamanan pangan. Tidak adanya pelindung lampu di ruang produksi menjadi kendala yang paling banyak dilakukan oleh UMKM dalam pemenuhan persyaratan CPPOB.

\section{DAFTAR PUSTAKA}

Ernawati, E. 2018. Pemenuhan persyaratan label produk pangan yang dijual secara online terhadap peraturan label pangan. Tesis. Sekolah Pascasarjana Institut Pertanian Bogor, Bogor.

Hapsari, I. M. 2014. Identifikasi berbagai permasalahan yang dihadapi oleh UKM dan peninjauan kembali regulasi UKM sebagai langkah awal revitalisasi UKM. Permana. 5(2):43-37.

Hartanto, R. \& S. Prabawa. 2020. Getuk keju frozen di Mojolaban Sukoharjo Jawa Tengah. PRIMA. 3(2):3842.

Hedynata, M. L. \& W. E. D. Hadianto. 2016. Strategi promosi dalam meningkatkan penjualan luscious chocolate potato snack. PERFORMA. 1(1):87-96.

Indoworo, H. E. 2016. Menumbuhkan jiwa wirausaha melalui peran sosial media. J. Inf. Upgr. 2(1):45-55.

Lyimo, J. M. 2017. Good manufacturing practices compliance : the case of registered small scale maize milling industries in Ubungo and Kinondoni districs, Tanzania. Disertasi. Muhimbili University of Health and Allied Sciences, Dar es-Salaam.

Ma'rifat, T. N. \& M. Sari. 2017. Penerapan sistem jaminan halal pada UMKM bidang olahan pangan hewani. J. Soc. Ded. 1(1):39-46.

Maryati, T., R. Syarief, \& R. Hasbullah. 2016. Analisis faktor kendala dalam pengajuan sertifikat halal (studi 
kasus : pelaku usaha mikro, kecil dan menengah makanan beku di jabodetabek). JIPTHP. 4(3):364-371.

Muhandri, T., D. Herawati, F. S. Budi, L. Nuraida, S. Koswaara, A. Z. Agista, \& Y. Sukmawati. 2016. Kesiapan usaha mikro kecil menengah pangan dalam penerapan ISO 9001:2008 (studi kasus di Palu, Sulawesi Tengah). Agrokreatif 2(2):61-66.

Mukantwali C., H. Laswai, B. Tiisekwa, \& S. Wiehler. 2013. Good manufacturing and hygienic practices at small and medium scale pineapple processing enterprises in Rwanda. Food. Sci. Qual. Manage. 13:15-30.

Nainggolan, R. 2016. Gender, tingkat pendidikan dan lama usaha sebagai determinan penghasilan UMKM Kota Surabaya. Kinerja. 20(1):1-12.

Ngwa, M. B. 2017. The application of good manufacturing practices as a quality approach to food safety in a food manufacturing establishment in the Western Cape South Africa. Tesis. Cape Peninsula University of Technology, Cape Town.

Nurcahyo, E. 2018. Pengaturan dan pengawasan produk pangan olahan kemasan. JMHU. 7(3):402-417.

Nurdiani, N. 2014. Teknik sampling snowball dalam penelitian lapangan. ComTech 5(2):1110-1118.

Pariadi, D. 2018. Pengawasan e-commerce dalam undangundang perdagangan dan undang-undang perlindungan konsumen. JHP. 48 (3):651-669.

Permana, S. D. H. \& M. Cendana. 2019. Pemanfaatan media sosial sebagai strategi promosi bagi kelangsungan UMKM. Ethos. 1(1):1-10.
Perdana, W. W. 2018. Penerapan GMP dan perencanaan pelaksanaan HACCP produk olahan pangan tradisional (mochi). Agroscience. 8(2):231-267.

Prastiwi, W. D., S. I. Santoso, \& S. Marzuki. 2017. Preferensi dan persepsi konsumsi produk nugget sebagai alternatif konsumsi daging ayam pada masyarakat di Kecamatan Secang Kabupaten Magelang. Agromedia. 35(1):65-72.

Santoso, I., S. A. Mustaniroh, \& D. Pranowo. 2018. Keakraban produk dan minat beli frozen food : peran pengetahuan produk, kemasan dan lingkungan sosial. J. Ilm. Kel. Kons. 11(2):134-144.

Singh, G. K. S., K. A. K. Ku Azman, M. A. A. Hadi, Z. Jaafar, \& M. M. R. M. M. Affandi. 2018. Scheduled and standardized training improved employees' knowledge on good manufacturing practices (GMP). Int. J. Pharm. Pharm. Sci. 10 (1):185-190.

Thaheer, H., S. Hasibuan, \& F. S. Mumpuni. 2015. Model resiko keamanan pangan produk pindang pada UMKM pengolahan ikan rakyat. PASTI IX. (3):275-285.

Utari, T. \& P. M. Dewi. 2014. Pengaruh modal, tingkat pendidikan dan teknologi terhadap pendapatan usaha mikro kecil dan menengah (UMKM) di kawasan Imam Bonjol Denpasar Barat. E. J. EP. Unud. 3(12):576-585.

Wijaya, W. A. \& W. P. Rahayu. 2014. Pemenuhan regulasi pelabelan produk industri rumah tangga pangan di Bogor. JMP. 1(1):65-73. 